\title{
Near-infrared spectroscopy as a potential method for identification of anatomically similar Japanese diploxylons
}

\section{AUTHOR(S):}

Horikawa, Yoshiki; Mizuno-Tazuru, Suyako; Sugiyama, Junji

\section{CITATION:}

Horikawa, Yoshiki ...[et al]. Near-infrared spectroscopy as a potential method for identification of anatomically similar Japanese diploxylons. Journal of Wood Science 2015, 61(3): 251-261

\section{ISSUE DATE:}

2015-01-31

URL:

http://hdl.handle.net/2433/201492

\section{RIGHT:}

The final publication is available at Springer via http://dx.doi.org/10.1007/s10086-015-1462-2.; The full-text file will be made open to the public on 31 January 2016 in accordance with publisher's 'Terms and Conditions for Self-Archiving', This is not the published version. Please cite only the published version.; この論文は出版社版でありません。引用の際 には出版社版をご確認ご利用ください。 
1 Near-infrared spectroscopy as a potential method for identification of anatomically

\section{2 similar Japanese diploxylons}

3

4 Yoshiki Horikawa*, Suyako (Mizuno) Tazuru, Junji Sugiyama

5

6 Research Institute for Sustainable Humanosphere, Kyoto University, Kyoto, Japan

7

8

$9 \quad$ Tel: $+81-774-38-3634$

$10 \quad$ Fax: $+81-774-38-3635$

11 E-mail: yhorikawa@ rish.kyoto-u.ac.jp

12

13 Keywords: Discriminant analysis; NIR spectroscopy; Japanese diploxylons; Wood

14 identification; Aging wood

15

16

17

18

19 


\section{Abstract}

A reliable technique for distinguishing anatomically similar diploxylons, Pinus

densiflora and $P$. thunbergii, was designed by employing near-infrared (NIR) spectroscopy in

combination with multivariate analysis. In total, 24 wood blocks, with half of them being of $P$.

24 densiflora and the rest of $P$. thunbergii, were selected from the collections of the Kyoto

25 University xylarium and scrutinized to build an acceptable model for discriminating between

the two species. The prediction model was constructed only from heartwood, and the best

performance was obtained for wavenumbers of $7300-4000 \mathrm{~cm}^{-1}$ in the second derivative

spectra. To apply this model to actual materials obtained from historical wooden buildings, 12

aging wood samples were analyzed and compared by microscopic identification.

Unexpectedly, the spectral differences between the species were smaller than those caused by

aging, and the prediction error was approximately 50\%. The spectra of the aging samples

were quite distinct in the specific region characteristic of absorbed water $\left(5220 \mathrm{~cm}^{-1}\right)$; this

was demonstrated clearly by principal component analysis. Therefore, for the proposed

model to be suitable for use in practical applications, further investigations of aging wood

samples and the corresponding spectroscopic data are necessary in order to understand the 


\section{Introduction}

Pinus densiflora and P. thunbergii are varieties of pine trees that are very popular in Japan. The former is known as akamatsu and mematsu, and the latter as kuromatsu and omatsu. Both are planted widely in Japan for timber production and as ornamental trees and are a characteristic feature of classical Japanese gardens. P. densiflora is commonly seen growing on the low mountains and hillsides, while $P$. thunbergii is native to the coastal areas. Anatomically, the two species are nearly identical in terms of the resin canal, which is surrounded by thin-walled epithelial cells and window-type cross-field pitting and exhibits a distinct transition from earlywood to latewood. The key difference between the two species was reported to be the degree of dentate thickening of the ray tracheids (Fig. 1). However, this difference is rather subjective and can be misleading, particularly in old samples, whose cell walls have nearly deteriorated. Consequently, in many previous studies, these pine wood species have been identified simply as diploxylons and their particular species has been left undecided. Therefore, an alternative method that could allow for the identification of the particular species without requiring special experimentation would be highly desirable.

In this regard, near-infrared (NIR) spectroscopy, which is known as a rapid, accurate and reproducible analysis technique, is an attractive choice. NIR spectroscopy is also suitable for assessing wood materials because the bands attributable to the vibrations of the chemical bonds involved in the formation of the cell wall allow for the direct and indirect estimation of 
57 the chemical and physical properties of the materials. When combined with multivariate analysis, NIR spectroscopy can be used to distinguish between different wood species.

Schimleck et al. demonstrated that principal component analysis (PCA) could be used to distinguish between pine and eucalyptus and also to differentiate between samples of the same eucalyptus species grown at different sites [1]. Soft independent modeling of class analogy has also been used to classify wood samples, including red and white oak [2] and larch species [3]. Regression analysis, especially partial least square (PLS) regression, is a powerful method of accurately estimating the chemical compositions of wood samples [4] and of determining their enzymatic hydrolysis [5] and decay resistance [6], in addition to their physical properties, such as fiber length [7-9], cellulose microfibril angle [10], and stiffness [11]. The method of distinguishing species coupled with regression analysis, called partial least squares-discriminant analysis (PLS-DA), has been used as a tool for differentiating true mahogany from three other similar species [12, 13]. Sandberg and Sterley [14] could successfully distinguish between heartwood and sapwood samples of Norway spruce using the PLS algorithm. Watanabe et al. [15] could differentiate between aging and degraded samples of softwood, such as Chamaecyparis obtusa, Torreya nucifera, and C. pisifera using PLS. In this study, we first describe a simple technique that uses NIR spectroscopy in combination with PLS-DA for distinguishing $P$. densiflora from $P$. thunbergii, which were 
76 classified at the xylarium of Kyoto University. The discriminant model was initially

77

78

79

80

81

82

83

84

85

86

87

88

89

90

91

92

93

examined using complete sets of the wood samples. Later, the sapwood and heartwood

samples were analyzed separately. Next, we demonstrate the applicability of the proposed

method in determining the species of aging samples of wood, and discuss the factors that

influence the precision of discrimination.

\section{Materials and methods}

\section{Sampling}

Wood blocks of $P$. densiflora designated as KYOw00029, 00225, 08058, 08059, 09268, 13942, 19360, and 19361, and those of P. thunbergii designated as KYOw00030, 00520, 05509, 05639, 08071, 10321, 11386, 13913, and 19176 by the xylarium at the Research Institute for Sustainable Humanosphere, Kyoto University (http://database.rish.kyoto-u.ac.jp/cgi-bin/bmi/en/namazu.cgi) were used for establishing the discriminant model. The wood samples in these blocks were collected from all the sapwood and heartwood zones. However, in the case of the wood blocks of KYOw00029, 05639, 08071, 09268, and 13913, only sapwood was collected. On the other hand, only heartwood was taken from KYOw00520, 19176, 19360, and 19361. Three parts were collected randomly from each wood block after NIR spectral analysis. Finally, wood samples from Chion-In temple in Kyoto, Japan and designated as KYO_ID_5165, 5166, 5168, 5170, 5173, $5175,5185,5187,5189,5192,5197$, and 5252 [16] were used to test applicability of the 
95 proposed method. Blocks were collected from each of these aging samples.

\section{Optical microscopy}

In the case of the wood samples obtained from the xylarium for the construction of

the calibration model, radial sections approximately $30 \mu \mathrm{m}$ in thickness were cut using a

sliding microtome and were stained with safranin. In the case of the wood samples from

100 Chion-in, the corresponding sections were obtained by hand sectioning and were not stained.

101 The sections were observed using a light microscope (Olympus BX51) equipped with a digital camera (Olympus DP73).

NIR spectroscopy

Each wood block after air-drying was milled with a rough file to produce a powder sample. Then, a tablet was prepared by collecting approximately $0.04 \mathrm{~g}$ of the powder, which was hand pressed following a previously published protocol [17]. The NIR spectrum was obtained using a PerkinElmer Spectrum 100N system for wavenumbers of $10000-4000 \mathrm{~cm}^{-1}$ at a spectral resolution of $16 \mathrm{~cm}^{-1} ; 32$ scans were made for each sample. The prepared tablet was placed directly on the NIR integrating sphere diffuse reflectance accessory (PerkinElmer),

110 which had a triglycine sulfate detector. Both faces of each tablet were scanned. The

111 absorbance spectrum was recorded by normalizing the single-beam spectrum against the

112 background spectrum using a Teflon-based material (Spectralon; LabSphere, North Sutton,

$113 \mathrm{NH}$ ). The original spectrum was treated using the Savitzky-Golay second derivative [18] 
114 using 9 points and a fifth-order polynomial for the smoothing before the multivariate

115 analysis.

\section{Multivariate analysis}

PLS-DA and PCA were performed using a commercial software (Unscrambler v.9.8;

118 CAMO Software, Inc., Woodbridge, NJ). Calibration and prediction samples from the 144

119 spectra (72 each for the sapwood and heartwood samples) were randomly selected as the ratio at 2 to1, that is, 96 were used for calibration, and 48 were used for the prediction set. Of the spectra used for calibration, 48 belonged to $P$. densiflora and 48 belonged to $P$. thunbergii. In the case of the spectra used for prediction, 24 belonged to $P$. densiflora and 24 belonged to $P$. thunbergii, as shown in Table 1. For the development of a discriminant model for use in the multivariate analysis, we assigned $P$. densiflora a class value of +1 and $P$. thunbergii a class value of -1 in the calibration set. The PLS factors were determined by cross validation; a single sample was kept out of the model, and its characteristics were predicted by constructing a model without the sample. Excessively high numbers may result in overfitting; therefore, the number of PLS factors was kept at fewer than 11. The coefficient of

129 determination for calibration $\left(R_{c}{ }^{2}\right)$ and the root mean square error of calibration (RMSEC) were used to assess the calibration performance. The models developed were evaluated by

131 using the coefficient of determination of prediction $\left(R_{p}{ }^{2}\right)$ and the root mean square error of 132 prediction (RMSEP). The percentage of correct prediction was determined as the proportion 
133 of the number of species discriminated correctly compared to the total number of samples

134 from prediction set. PLS-DA to distinguish between sapwood and heartwood was also

135 performed using the same procedure.

PCA was performed on the basis of the second derivative spectra of all the wood

137 samples for wavenumbers of $7300-4000 \mathrm{~cm}^{-1}$. The PC loading was obtained from the model

138 built for score plots.

139 Results and Discussion

140 Discriminant model for determining the type of wood present

Fig. 2a and $\mathrm{b}$ show original and second derivative spectra from heart and sapwood samples of $P$. densiflora and $P$. thunbergii. From the band at $5220 \mathrm{~cm}^{-1}$ assigned to absorbed water in second derivative NIR spectra, sapwood samples seemed higher moisture contents than those of heartwood. However, it was difficult to identify whether $P$. densiflora or $P$. thunbergii from spectra because spectral pattern including the bands at 5980 and 5800 specific to lignin and hemicellulose respectively, were almost same between these species.

147 Therefore, we applied multivariate analysis and Table 2 shows the statistical summary of the

148 discriminant models obtained on the basis of the original spectra and the second derivative

149 spectra. To generate a better model, the regions of the NIR spectra corresponding to the 150 wavenumbers of $10000-4000 \mathrm{~cm}^{-1}$ were separated into four distinct ranges on the basis of the 151 properties of the molecular vibrations. In the first range $\left(10000-7300 \mathrm{~cm}^{-1}\right)$, the second or 
152 third overtones were involved, although less information was obtained from the wood

153 samples. The second range $\left(7300-6050 \mathrm{~cm}^{-1}\right)$ mainly corresponded to $\mathrm{OH}$ overtone vibrations.

154 The third range $\left(6050-5500 \mathrm{~cm}^{-1}\right)$ corresponded to the $\mathrm{CH}$ vibrations and the vibrations from

155 the aromatic framework, while in the fourth range $\left(5500-4000 \mathrm{~cm}^{-1}\right)$, several combinatorial

156 vibrations were present.

157

For the samples containing both sapwood and heartwood, the discriminant models

shown in Table 2a were constructed on the basis of the NIR spectra without subjecting the

spectra to any spectral pretreatment. All the models were unreliable because the $R_{p}{ }^{2}$ values

were less than 0.60. Next, we obtained the second derivative spectra and created the

discriminant models shown in Table $2 \mathrm{~b}$. Secondary differentiation can extract information

hidden in the original spectra. Thus, researchers have often applied this algorithm to construct

regression models. This spectral pretreatment decreased the number of factors relatively;

however, the models obtained were not markedly better. Fig. 3a shows a histogram

corresponding to the discriminant model based on the second derivative spectra for 7300

$4000 \mathrm{~cm}^{-1}$. In this region, a few samples of both P. densiflora and P. thunbergii had class

values of approximately 0 , which indicated that this model could not be used for

distinguishing between the two species.

Sapwood could, therefore, be distinguished from heartwood, and discriminant

models could be built, as summarized in Tables $2 \mathrm{c}$ and $\mathrm{d}$. However, as was the case with the 
171 dataset corresponding to the samples containing both sapwood and heartwood, all the models

172 showed poor performances, as the $R_{p}{ }^{2}$ values were lower than 0.75 . Fig. $3 \mathrm{~b}$ shows a

173 histogram based on the second derivative spectra for $7300-4000 \mathrm{~cm}^{-1}$; for this region, the

174 RMSEP value was 0.54 and the $R_{p}{ }^{2}$ value was 0.71 , with some of the prediction samples from

$P$. thunbergii having class values of 0 and similar to those of $P$. densiflora.

In the case of heartwood, even though a large number of factors were required, the

calibration performance was comparatively better (Table 2e). However, the models obtained

using the vibrations over $10000-7300 \mathrm{~cm}^{-1}$ and $7300-6050 \mathrm{~cm}^{-1}$ were less reliable; this was

particularly true in the latter case, where the major bands were assigned to cellulose [19-21].

This suggested that the cellulose contents were indistinct between $P$. densiflora and $P$.

thunbergii as well as their crystalline properties.

The discriminant models obtained using the second derivative spectra are shown in

Table 2f. The models exhibited better performances as the $R_{p}{ }^{2}$ values corresponding to a few

of the NIR spectral regions were higher than 0.85 . The best performance was obtained for

$7300-4000 \mathrm{~cm}^{-1}$; this region showed an RMSEP value of $0.37, R_{p}{ }^{2}$ value of 0.86 and $100 \%$ accuracy of identification. As shown in Fig. 3c, the prediction model based on the and had negative values. 
192 the difficulties encountered in classification using sapwood samples indicated that the chemical natures of $P$. densiflora and $P$. thunbergii were essentially indistinct. However, the

194 fact that using heartwood samples yielded better results suggested that the heartwood components of the two species might be slightly different.

\section{Applicability in investigating aging wood used in traditional buildings}

The applicability of the regression model developed was tested by reexamining actual wood materials used in traditional wooden buildings built in the medieval period.

Chion-In temple in Kyoto is well known and is the main temple of Jōdo Shū ("The Pure Land during 2005-2010, and 25 wood samples had been classified as being of diploxylons [16]. tracheids of these samples are shown in Fig. 4. Of these 12 samples, only three were anatomically identified as $P$. thunbergii on the basis of the degree of dentate thickening in the ray tracheids. The PLS-DA models built up on the basis of heartwood were used in the identification of these materials. The percentage of coincidence with the anatomical

207 identification results is listed in Table 3. In contrast to the prediction set samples shown in 
209 reason behind this failure seems to be the fact that the wood used in Chion-in was sapwood,

210 while the calibration models used for identification were created using heartwood. However,

211 sapwood is usually not used as a building material, in order to minimize deterioration and

212 maintain the structural strength. Given this background, we investigated these aging wood

213 samples further using NIR spectroscopy in combination with multivariate analysis, as

214 mentioned in the next segment.

\section{Effects of aging}

217 carried out in the wavenumber range $7300-4000 \mathrm{~cm}^{-1}$ of the second derivative spectra (Fig.

218 5a). The score plots showed that some of the wood samples from Chion-In temple localized

219 on the left side and far from those belonging to $P$. densiflora and $P$. thunbergii. It is known

220 that noncrystalline polysaccharides such as hemicellulose decrease in quantity in aging

221 samples of C. obtusa, whereas the crystalline cellulose region is not affected [22].

222 Furthermore, Yokoyama et al. reported that the equilibrium moisture content in C. obtusa

223 decreases after aging [23]. Therefore, it seems that aging under dry conditions degraded the

224 hemicelluloses, which are the adsorption sites for water in wood materials, resulting in a

225 decrease in the equilibrium moisture content. In this regard, the wood samples from Chion-in

226 temple were different in that there was no statistical difference between modern and aging

227 woods in hemicellulose contents, given the presence of the band at approximately $5800 \mathrm{~cm}^{-1}$; 
228 this band is specific to furanose/pyranose, which form from hemicellulose [24] and exhibited

229 a value of almost 0 in the PC1 loading (Fig. 5b). In addition, the amount of absorbed water in

230 the Chion-in samples was higher, as a positive band was noticed at approximately $5220 \mathrm{~cm}^{-1}$

231 and was assignable to the combinational vibration of water; this was clearly visible in the

232 PC1 loading. Moreover, the lignin content of the Chion-in samples was lower, as a band was

233 noticed at $5970 \mathrm{~cm}^{-1}$; this band is characteristic of aromatic skeletal vibrations [24] and

234 exhibited negative values during PC1 loading. These interpretation was supported by the comparison with the second derivative spectra between modern and aging wood (Fig. 5c).

Therefore, the lignin in the Chion-in samples seemed to be modified to a greater degree than

was the hemicellulose, which resulted in a decrease in the hydrophobicity, as this increased

the amount of absorbed water. These features were not observed in the spectra of the unaging

wood samples. Hence, the samples from Chion-in could not be classified accurately. In order

to be able to employ the proposed classification method for identifying historical and archeological wood samples, we have to consider the effects of aging on the characteristics of the samples, including on the quantity of absorbed water and the chemical components such as lignin and polysaccharides, whose chemical structure can be changed by oxidative and/or enzymatic reactions. Therefore, further investigations need to be performed to determine the optimal conditions for measurements as well as suitable data treatments to account for the 
247 and $P$. thunbergii on the basis of the differences in their spectra.

\section{Conclusions}

When using unaging heartwood samples, we were able to identify $P$. densiflora and $P$.

thunbergii by employing NIR spectroscopy in combination with multivariate analysis.

However, when aging wood samples were used, the proposed method was ineffective in

distinguishing between the two species. Thus, the method is not suitable for classifying wood

to find the spectral features between these microscopically similar species more significant

than those caused by aging.

256

257

\section{Acknowledgments}

The study was supported in parts by Grants-in-Aid for Scientific Research (Grant Numbers 25252033, 22300309, and 24780169) from the Japan Society for the Promotion of Science (JSPS). The authors thank Ms. Izumi Kanai and Mr. Akio Adachi for their technical support.

\section{References}

262

[1] Schimleck LR, Evans R, Ilic J, Matheson AC (2002) Estimation of wood stiffness of

263 increment cores by near-infrared spectroscopy. Can J For Res 32: 129-135

(Quercus rubra) and white oak (Quercus alba) wood using a near infrared spectrometer and 
267 [3] Gierlinger N, Schwanninger M, Wimmer R (2004) Characteristics and classification 268 of Fourier-transform near infrared spectra of the heartwood of different larch species (Larix

269 sp.). J Near Infrared Spectrosc 12: 113-119

270 [4] Jones PD, Schimleck LR, Peter GF, Daniels RF, Clark A (2006) Nondestructive

271 estimation of wood chemical composition of sections of radial wood strips by diffuse

272 reflectance near infrared spectroscopy. Wood Sci Technol 40: 709-720

273 [5] Horikawa Y, Imai T, Takada R, Watanabe T, Takabe K, Kobayashi Y, Sugiyama J

274 (2012) Chemometric analysis with near-infrared spectroscopy for chemically pretreated

275 Erianthus toward efficient bioethanol production. Appl Biochem Biotechnol 166: 711-721

276 [6] Leinonen A, Harju AM, Venalainen M, Saranpaa P, Laakso T (2008) FT-NIR

277 spectroscopy in predicting the decay resistance related characteristics of solid Scots pine

278 (Pinus sylvestris L.) heartwood. Holzforschung 62: 284-288

279 [7] Hauksson JB, Bergqvist G, Bergsten U, Sjostrom M, Edlund U (2001) Prediction of

280 basic wood properties for Norway spruce. Interpretation of near infrared spectroscopy data

281 using partial least squares regression. Wood Sci Technol 35: 475-485

282 [8] Inagaki T, Schwanninger M, Kato R, Kurata Y, Thanapase W, Puthson P, 283 Tsuchikawa S (2010) Eucalyptus camaldulensis density and fiber length estimated by 284 near-infrared spectroscopy. Wood Sci Technol 46: 143-155

285 [9] Schimleck LR, Jones RD, Peter GF, Daniels RF, Clark A (2004) Nondestructive 
286 estimation of tracheid length from sections of radial wood strips by near infrared 287 spectroscopy. Holzforschung 58: 375-381

288 [10] Schimleck LR, Evans R, Jones PD, Daniels RF, Peter GF, Clark A (2005) 289 Estimation of microfibril angle and stiffness by near infrared spectroscopy using sample sets 290 having limited wood density variation. IAWA J 26: 175-187

291 [11] Schimleck LR, Michell AJ, Vinden P (1996) Eucalypt wood classification by NIR 292 spectroscopy and principal components analysis. Appita J 49: 319-324

293 [12] Braga JWB, Pastore TCM, Coradin VTR, Camargos JAA, da Silva AR (2011) The 294 use of near infrared spectroscopy to identify solid wood specimens of Swietenia Macrophylla 295 (Cites Appendix II). IAWA J 32: 285-296

296 [13] Pastore TCM, Braga JWB, Coradin VTR, Magalhaes WLE, Okino EYA, Camargos 297 JAA, de Muniz GIB, Bressan OA, Davrieux F (2011) Near infrared spectroscopy (NIRS) as a 298 potential tool for monitoring trade of similar woods: Discrimination of true mahogany, cedar, 299 andiroba, and curupixa. Holzforschung 65: 73-80

300 [14] Sandberg K, Sterley M (2009) Separating Norway spruce heartwood and sapwood in 301 dried condition with near-infrared spectroscopy and multivariate data analysis. Eur J For Res 128: $475-481$

303 [15] Watanabe K, Abe H, Kataoka Y, Nodhito S (2011) Species separation of aging and 
305 [16] Mizuno S, Sugiyama J (2011) Wood identification of building components of

306 Syue-do, Chion-in temple designated as nationally important cultural property. J Soc

307 Architect Hits Japan 56: 124-135

308 [17] Horikawa Y, Imai T, Takada R, Watanabe T, Takabe K, Kobayashi Y, Sugiyama J

309 (2011) Near-infrared chemometric approach to exhaustive analysis of rice straw pretreated

310 for bioethanol conversion. Appl Biochem Biotechnol 164: 194-203

311 [18] Savitzky A, Golay MJE (1964) Smoothing and differentiation of data by simplified

312 least squares procedures. Anal Chem 36: 1627-1639

313 [19] Tsuchikawa S, Siesler HW (2003a) Near-infrared spectroscopic monitoring of the

314 diffusion process of deuterium-labeled molecules in wood. Part I: Softwood. Appl Spectrosc

$315 \quad$ 57: $667-674$

316 [20] Tsuchikawa S, Siesler HW (2003b) Near-infrared spectroscopic monitoring of the

317 diffusion process of deuterium-labeled molecules in wood. Part II: Hardwood. Appl

$318 \quad$ Spectrosc. 57: 675-681

319 [21] Watanabe A, Morita S, Ozaki Y (2006) A study on water adsorption onto

320 microcrystalline cellulose by near-infrared spectroscopy with two-dimensional correlation

321 spectroscopy and principal component analysis. Appl Spectrosc 60: 1054-1061

322 [22] Tsuchikawa S, Yonenobu H, Siesler HW (2005) Near-infrared spectroscopic 
324 method. Analyst 130: 379-384

325 [23] Yokoyama M, Gril J, Matsuo M, Yano H, Sugiyama J, Clair B, Kubodera S,

326 Mitsutani T, Sakamoto M, Ozaki H, Imamura M, Kawai S (2009) Mechanical characteristics

327 of aged Hinoki wood from Japanese historical buildings. C R Physique 10: 601-611

328 [24] Siesler HW, Ozaki Y, Kawata S, Heise HW Near-infrared Spectroscopy, Principal

329 Instruments, Applications; Willey-VCH Verlag GmbH, Weinhem, Germany, 2002

330 
$331 \quad$ Figures

332

(a)

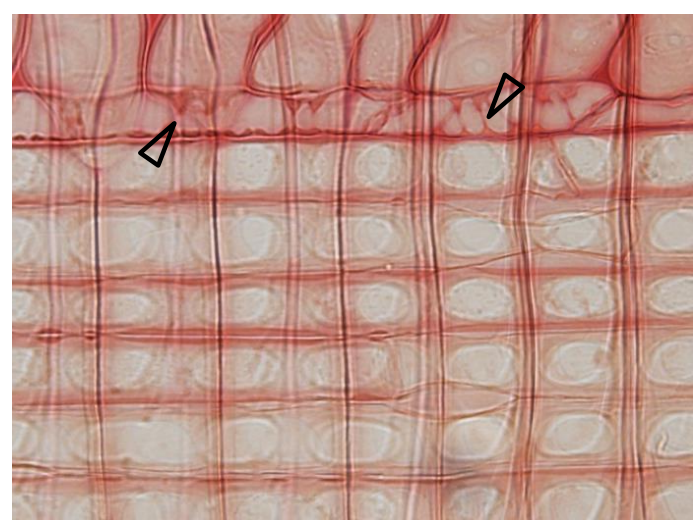

(b)

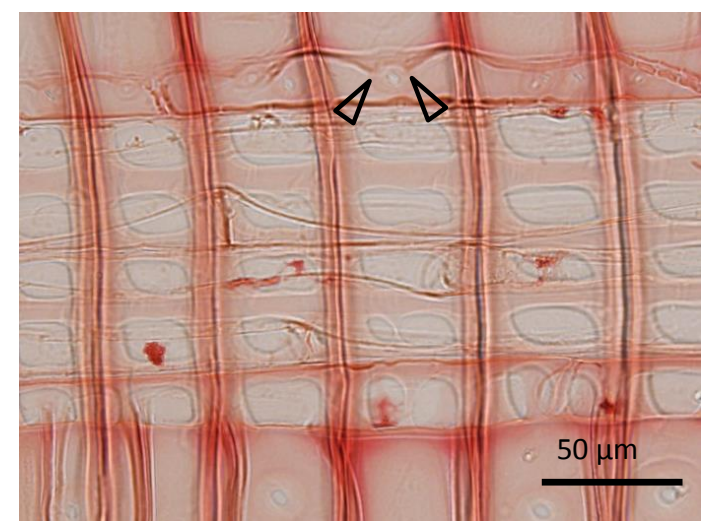

334 Fig. 1

335 
(a)

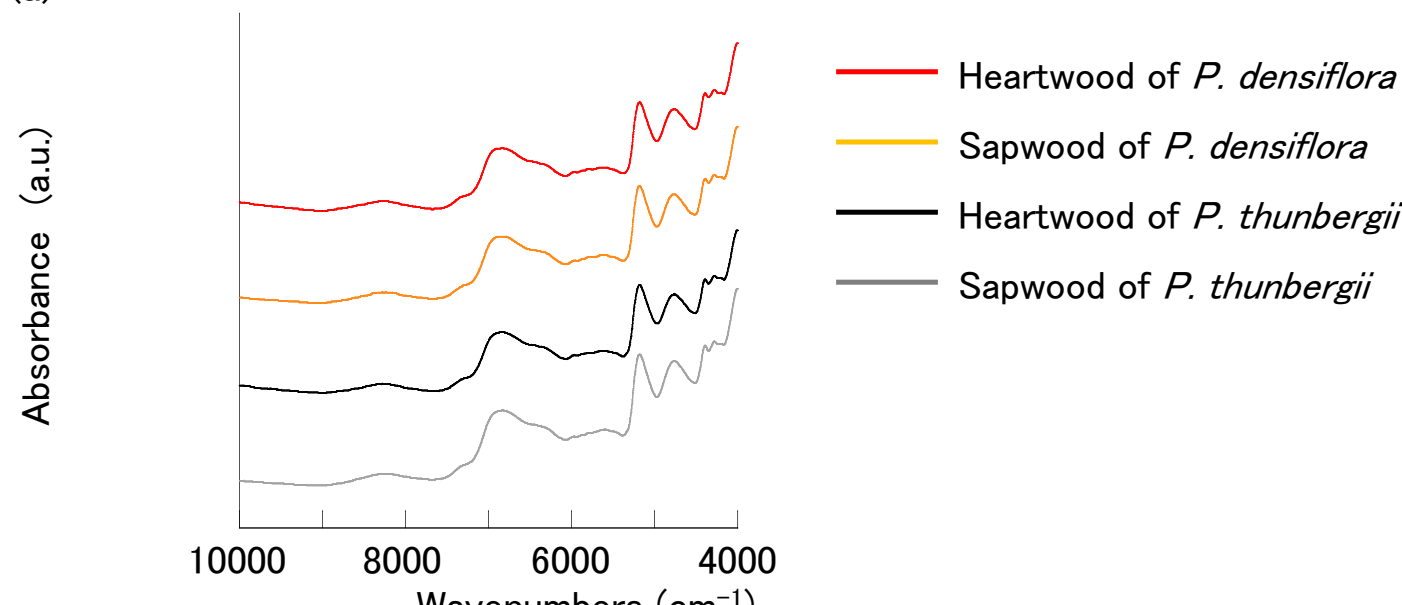

(b)

336

Wavenumbers $\left(\mathrm{cm}^{-1}\right)$

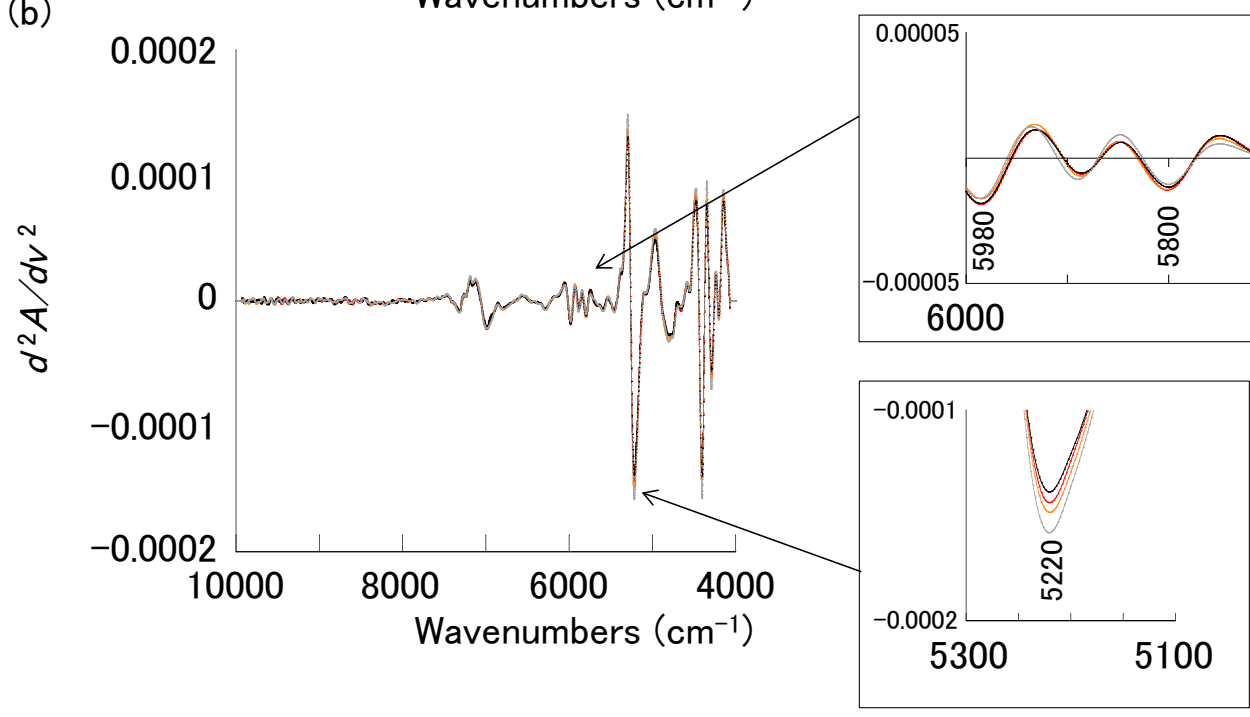

337

338

Fig. 2

339

340

341

342 

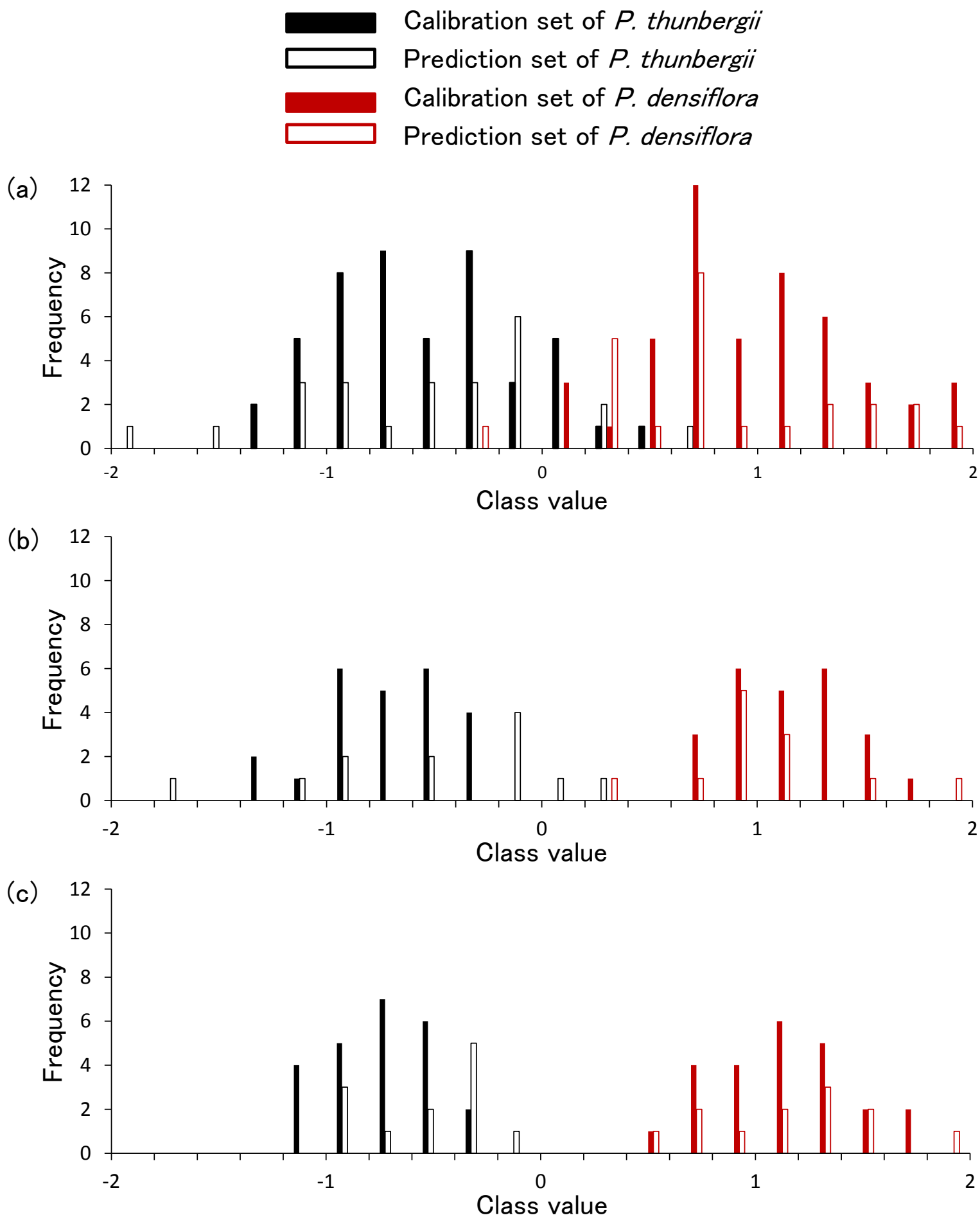

Fig. 3 

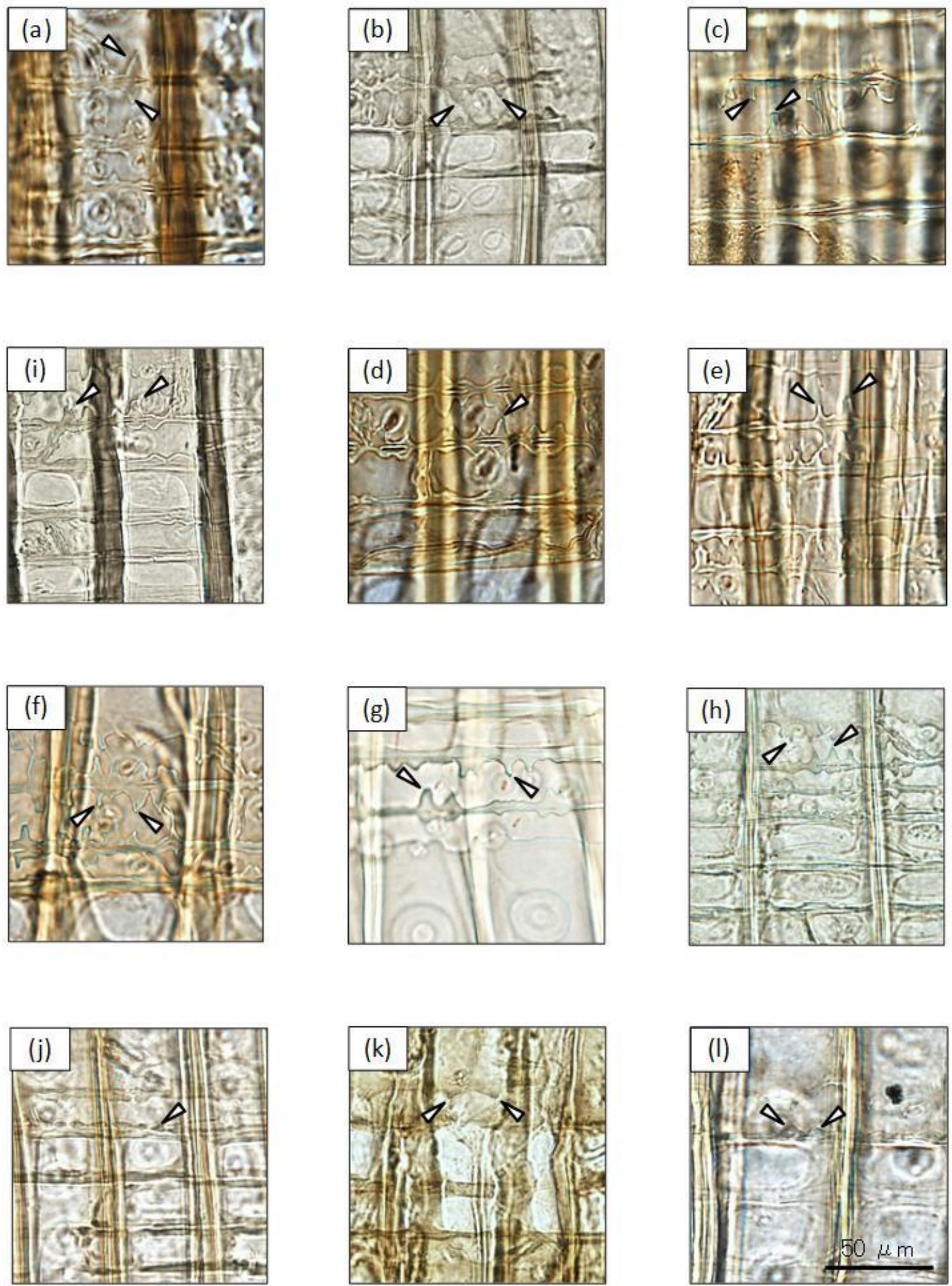

$348 \quad$ Fig. 4 


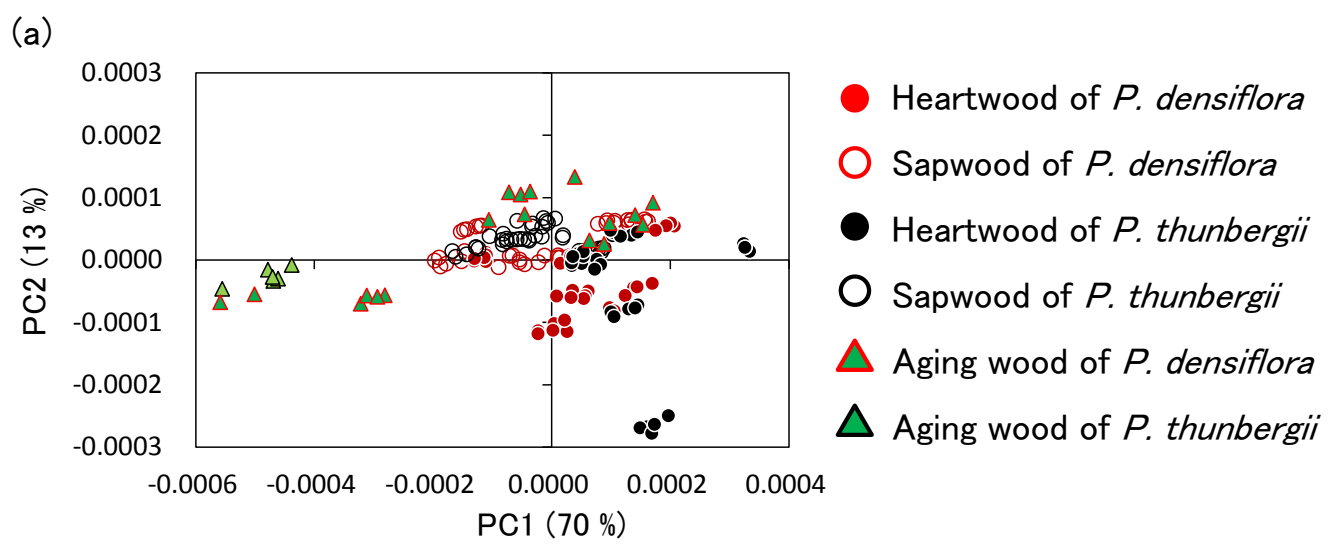

(b)
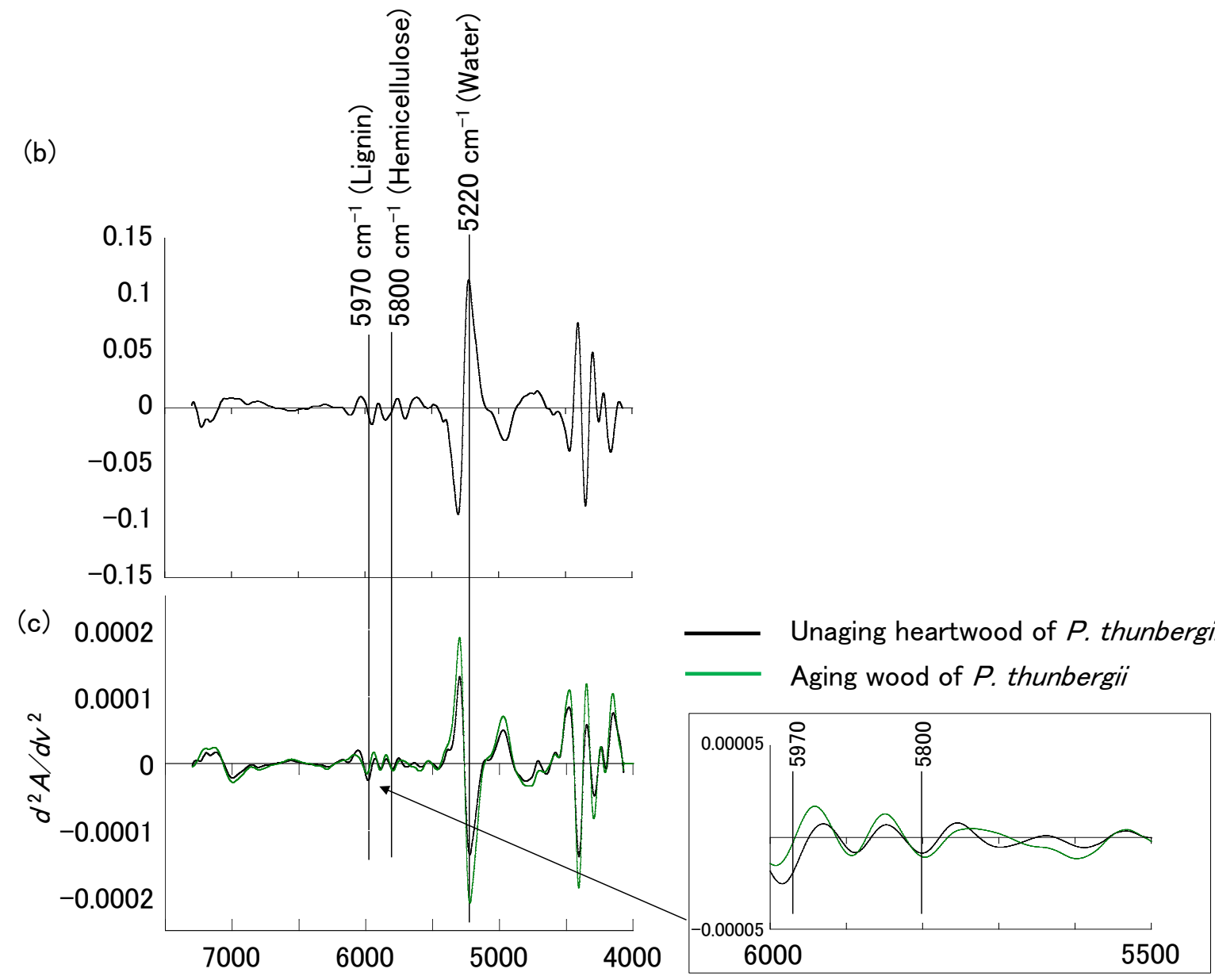

Wavenumbers $\left(\mathrm{cm}^{-1}\right)$

$350 \quad$ Fig. 5 


\section{$352 \quad$ Figure legends}

353 Fig. 1. Optical micrographs of the standard radial section. (a) P. densiflora shows dentate

354 thickening within the ray tracheid, while (b) these features are smooth in $P$. thunbergii. The arrow heads indicate dentate thickening.

356

Fig. 2. (a) Original NIR spectra of heartwood and sapwood from $P$. densiflora and $P$. thunbergii designated as KYOw13942 and 00030, which were included in calibration set. (b)

Second derivative spectra obtained from the 4 spectra in (a).

Fig. 3. Histograms of the class values computed by PLS-DA on the basis of the second derivative spectra for wavenumbers of $7300-4000 \mathrm{~cm}^{-1}$ and obtained from (a) a mixture of sapwood and heartwood, (b) sapwood, and (c) heartwood.

Fig. 4. Optical micrographs of the radial sections acquired from wood samples from Chion-In 5185, 5189, and 5252, respectively, which were identified as being of $P$. densiflora. The images in (j)-(1), which were acquired from KYO_ID_5187, 5192, and 5197, respectively, were identified as being of $P$. thunbergii. The arrow heads indicate dentate thickening. 
371 Fig. 5. (a) The principal components analysis (PCA) scores plotted on the first and second 372 principal components on the basis of the second derivative NIR spectra in the $7300-4000$ $373 \mathrm{~cm}^{-1}$ region.

374 (b) The spectrum obtained from PC1 loading in PCA. The bands at 5970, 5800, and 5220

$375 \mathrm{~cm}^{-1}$ are assigned to lignin, hemicellulose, and the absorbed water, respectively.

376 (c) Second derivative spectra obtained from unaging heartwood and aging wood of $P$. 377 thunbergii designated as KYOw19176 and KYO_ID_5197. 
1 Table 1. The number of NIR spectra of the wood samples used for calibration and prediction.

2

\begin{tabular}{llccc}
\hline & & Calibration set & Prediction set & Total \\
\hline \multirow{2}{*}{ P. densiflora } & Sapwood & 24 & 12 & 36 \\
& Heartwood & 24 & 12 & 36 \\
\hline \multirow{2}{*}{ P. thunbergii } & Sapwood & 24 & 12 & 36 \\
& Heartwood & 24 & 12 & 36 \\
\hline Total & & 96 & 48 & 144 \\
\hline
\end{tabular}

3

4

5

6

7

8

9

10

11

12

13

14

15 
16 Table 2. Statistical summary of the discriminant models based on the calibration and

17 prediction sets obtained from a mixture of sapwood and heartwood samples (a and b), and

18 individual sapwood (c and d) and heartwood (e and f) samples. The discriminant models were

19 obtained by using the original spectra (a, c and e) and the second derivative spectra (b, $\mathrm{d}$ and

20 f). A schematic illustration is shown on the left to indicate each spectral region.

(a)

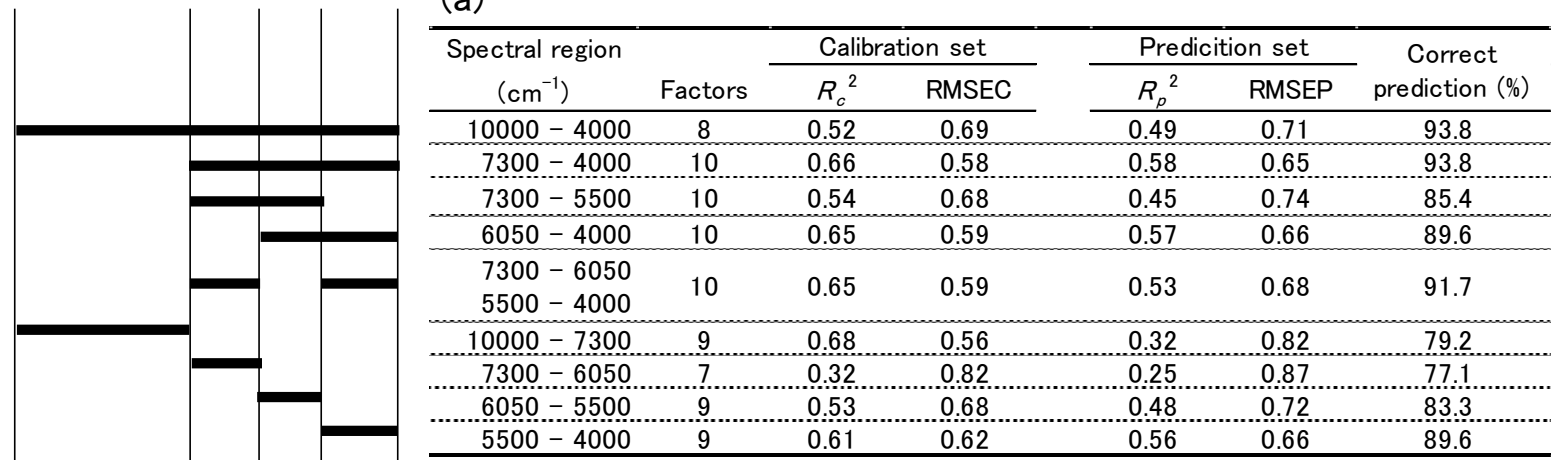

(b)

\begin{tabular}{|c|c|c|c|c|c|c|}
\hline \multirow{2}{*}{$\begin{array}{c}\text { Spectral region } \\
\left(\mathrm{cm}^{-1}\right)\end{array}$} & \multirow[b]{2}{*}{ Factors } & \multicolumn{2}{|c|}{ Calibration set } & \multicolumn{2}{|c|}{ Predicition set } & \multirow{2}{*}{$\begin{array}{c}\text { Correct } \\
\text { prediction (\%) }\end{array}$} \\
\hline & & $R_{c}{ }^{2}$ & RMSEC & $R_{p}{ }^{2}$ & RMSEP & \\
\hline $10000-4000$ & 7 & 0.72 & 0.53 & 0.54 & 0.68 & 89.6 \\
\hline $7300-4000$ & 9 & 0.75 & 0.50 & 0.56 & 0.66 & 91.7 \\
\hline $7300-5500$ & 10 & 0.69 & 0.56 & 0.56 & 0.66 & 93.8 \\
\hline $6050-4000$ & 8 & 0.72 & 0.53 & 0.54 & 0.68 & 87.5 \\
\hline $\begin{array}{l}7300-6050 \\
5500-4000\end{array}$ & 8 & 0.71 & 0.54 & 0.55 & 0.67 & 89.6 \\
\hline $10000-7300$ & 2 & 0.42 & 0.76 & 0.23 & 0.88 & 68.8 \\
\hline $7300-6050$ & 2 & 0.33 & 0.82 & 0.28 & 0.85 & 72.9 \\
\hline $6050-5500$ & 10 & 0.56 & 0.66 & 0.53 & 0.69 & 81.3 \\
\hline $5500-4000$ & 8 & 0.69 & 0.56 & 0.52 & 0.69 & 85.4 \\
\hline
\end{tabular}


(c)

\begin{tabular}{|c|c|c|c|c|c|c|}
\hline \multirow{2}{*}{$\begin{array}{c}\text { Spectral region } \\
\left(\mathrm{cm}^{-1}\right)\end{array}$} & \multirow[b]{2}{*}{ Factors } & \multicolumn{2}{|c|}{ Calibration set } & \multicolumn{2}{|c|}{ Predicition set } & \multirow{2}{*}{$\begin{array}{c}\text { Correct } \\
\text { prediction (\%) }\end{array}$} \\
\hline & & $R_{c}{ }^{2}$ & RMSEC & $R_{0}{ }^{2}$ & RMSEP & \\
\hline $10000-4000$ & 10 & 0.91 & 0.30 & 0.74 & 0.51 & 91.7 \\
\hline $7300-4000$ & 9 & 0.90 & 0.31 & 0.69 & 0.56 & 87.5 \\
\hline $7300-5500$ & 5 & 0.35 & 0.80 & 0.30 & 0.84 & 75.0 \\
\hline $6050-4000$ & 10 & 0.90 & 0.32 & 0.64 & 0.60 & 87.5 \\
\hline $\begin{array}{l}7300-6050 \\
5500-4000\end{array}$ & 10 & 0.87 & 0.36 & 0.65 & 0.59 & 87.5 \\
\hline $10000-7300$ & 7 & 0.73 & 0.52 & 0.21 & 0.89 & 83.3 \\
\hline $7300-6050$ & 6 & 0.33 & 0.82 & 0.01 & 1.07 & 54.2 \\
\hline $6050-5500$ & 9 & 0.77 & 0.48 & 0.39 & 0.78 & 79.2 \\
\hline $5500-4000$ & 10 & 0.86 & 0.38 & 0.60 & 0.63 & 87.5 \\
\hline
\end{tabular}

(d)

\begin{tabular}{|c|c|c|c|c|c|c|}
\hline \multirow{2}{*}{$\begin{array}{c}\text { Spectral region } \\
\left(\mathrm{cm}^{-1}\right)\end{array}$} & \multirow[b]{2}{*}{ Factors } & \multicolumn{2}{|c|}{ Calibration set } & \multicolumn{2}{|c|}{ Predicition set } & \multirow{2}{*}{$\begin{array}{c}\text { Correct } \\
\text { prediction (\%) }\end{array}$} \\
\hline & & $R_{c}{ }^{2}$ & RMSEC & $R_{0}{ }^{2}$ & RMSEP & \\
\hline $10000-4000$ & 5 & 0.79 & 0.46 & 0.59 & 0.64 & 87.5 \\
\hline $7300-4000$ & 8 & 0.91 & 0.30 & 0.71 & 0.54 & 95.8 \\
\hline $7300-5500$ & 4 & 0.72 & 0.53 & 0.67 & 0.58 & 87.5 \\
\hline $6050-4000$ & 8 & 0.88 & 0.35 & 0.66 & 0.58 & 95.8 \\
\hline $\begin{array}{l}7300-6050 \\
5500-4000\end{array}$ & 6 & 0.74 & 0.51 & 0.64 & 0.60 & 87.5 \\
\hline $10000-7300$ & 1. & 0.19 & 0.90 & 0.02 & 0.99 & 54.2 \\
\hline $7300-6050$ & 5 & 0.64 & 0.60 & 0.33 & 0.82 & 75.0 \\
\hline $6050-5500$ & 5 & 0.65 & 0.59 & 0.59 & 0.64 & 91.7 \\
\hline $5500-4000$ & 6 & 0.72 & 0.53 & 0.61 & 0.62 & 87.5 \\
\hline
\end{tabular}



(e)

spectratregion

\begin{tabular}{|c|c|c|c|c|c|c|}
\hline \multirow{2}{*}{$\begin{array}{c}\text { Spectral region } \\
\left(\mathrm{cm}^{-1}\right)\end{array}$} & \multirow[b]{2}{*}{ Factors } & \multicolumn{2}{|c|}{ Calibration set } & \multicolumn{2}{|c|}{ Predicition set } & \multirow{2}{*}{$\begin{array}{c}\text { Correct } \\
\text { prediction (\%) }\end{array}$} \\
\hline & & $R_{c}{ }^{2}$ & RMSEC & $R_{p}{ }^{2}$ & RMSEP & \\
\hline $10000-4000$ & 9 & 0.92 & 0.28 & 0.80 & 0.45 & 100 \\
\hline $7300-4000$ & 9 & 0.93 & 0.27 & 0.75 & 0.50 & 97.9 \\
\hline $7300-5500$ & 7 & 0.81 & 0.44 & 0.77 & 0.48 & 100 \\
\hline $6050-4000$ & 9 & 0.93 & 0.27 & 0.81 & 0.43 & 100 \\
\hline $\begin{array}{l}7300-6050 \\
5500-4000\end{array}$ & 9 & 0.91 & 0.30 & 0.78 & 0.47 & 100 \\
\hline $10000-7300$ & 8 & 0.81 & 0.44 & 0.56 & 0.67 & 93.8 \\
\hline $7300-6050$ & 10 & 0.86 & 0.37 & 0.65 & 0.59 & 95.8 \\
\hline $6050-5500$ & 9 & 0.91 & 0.30 & 0.84 & 0.40 & 100 \\
\hline $5500-4000$ & 10 & 0.95 & 0.22 & 0.83 & 0.42 & 100 \\
\hline
\end{tabular}

(f)

\begin{tabular}{|c|c|c|c|c|c|c|}
\hline \multirow{2}{*}{$\begin{array}{c}\text { Spectral region } \\
\left(\mathrm{cm}^{-1}\right)\end{array}$} & \multirow[b]{2}{*}{ Factors } & \multicolumn{2}{|c|}{ Calibration set } & \multicolumn{2}{|c|}{ Predicition set } & \multirow{2}{*}{$\begin{array}{c}\text { Correct } \\
\text { prediction (\%) }\end{array}$} \\
\hline & & $R_{c}{ }^{2}$ & RMSEC & $R_{p}{ }^{2}$ & RMSEP & \\
\hline $10000-4000$ & 8 & 0.97 & 0.18 & 0.83 & 0.41 & 100 \\
\hline $7300-4000$ & 7. & 0.92 & 0.28 & 0.86 & 0.37 & 100 \\
\hline $7300-5500$ & 8. & 0.91 & 0.30 & 0.73 & 0.52 & 95.8 \\
\hline $6050-4000$ & 7. & 0.92 & 0.29 & 0.86 & 0.38 & 100 \\
\hline $\begin{array}{l}7300-6050 \\
5500-4000\end{array}$ & 7 & 0.92 & 0.28 & 0.85 & 0.39 & 100 \\
\hline $10000-7300$ & 7 & 0.98 & 0.12 & 0.46 & 0.74 & 75.0 \\
\hline $7300-6050$ & 5. & 0.82 & 0.43 & 0.48 & 0.72 & 87.5 \\
\hline $6050-5500$ & 10 & 0.90 & 0.31 & 0.81 & 0.44 & 100 \\
\hline $5500-4000$ & 7 & 0.91 & 0.30 & 0.85 & 0.39 & 100 \\
\hline
\end{tabular}


29 Table 3. Prediction accuracies of the wooden materials used in Chion-In temple as functions

30 of the spectral pretreatment and spectral range. The predictions were made by employing the

31 discriminant models based on the original and second derivative spectra of the heartwood

32 sample for wavenumbers of $7300-4000 \mathrm{~cm}^{-1}$. A schematic illustration is provided on the left

33 to show each spectral region.

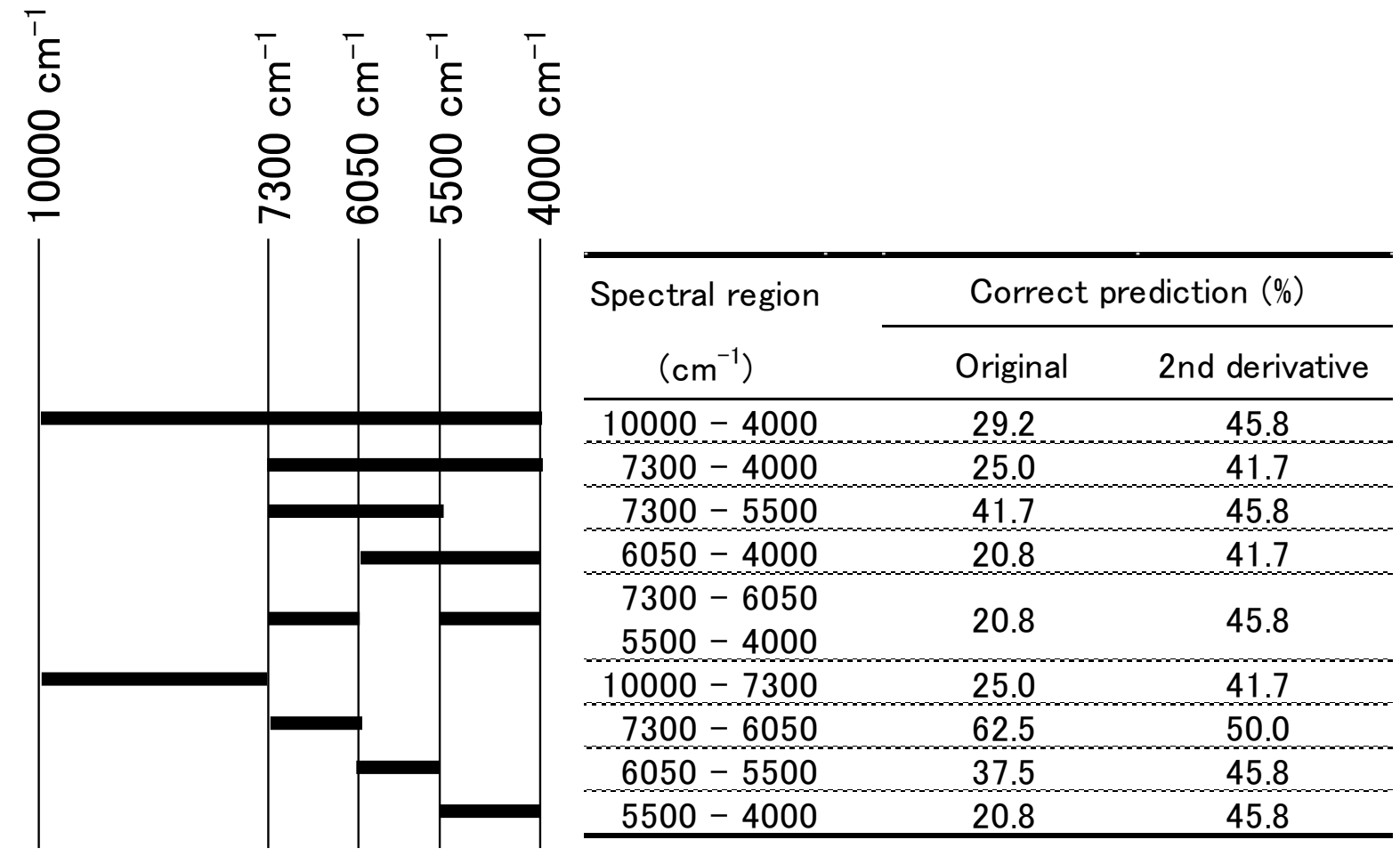

